\title{
Montelukast Has no Impact on the Systemic Production of TGF $\beta-1$ in Patients with Nasal Polyposis Associated with Aspirin Intolerance
}

\author{
Rogério Pezato ${ }^{1}$ Luciano Lobato Gregório ${ }^{1}$ Claudina Pérez-Novo ${ }^{1}$ Thiago Ferreira Pinto Bezerra ${ }^{2}$ \\ Eduardo Macoto Kosugi ${ }^{1}$ \\ ${ }^{1}$ Department of Otorhinolaryngology - Head and Neck Surgery, \\ Universidade Federal de São Paulo, São Paulo, Brazil \\ ${ }^{2}$ Department of Otorhinolaryngology, Universidade Federal de \\ Pernambuco, Recife, Pernambuco, Brazil \\ Address for correspondence Rogério Pezato, MD, PhD, Departmento \\ de Otorrinolaringologia - Cirurgia de Pescoço e Cabeça, Rua dos \\ Otonis700, Piso Superior, 04025-002, São Paulo, SP, Brazil \\ (e-mail: pezatobau@gmail.com).
}

Int Arch Otorhinolaryngol 2021;25(1):e88-e91.

\begin{abstract}
Introduction Nasal polyposis is a disease characterized by a mechanical dysfunction of the nasal mucosa, closely related to the unique makeup of its extracellular matrix, which develops as the result of an anomalous tissue remodeling process.

Transforming growth factor beta 1 (TGF- $\beta 1$ ) is reduced not only in the nasal polypoid tissue, but also in the plasma of aspirin-intolerant patients. These patients exhibit an imbalance in the production of eicosanoids characterized by an increase in leukotrienes. Thus, it is important that the relationship between the production of leukotrienes and TGF- $\beta 1$ be assessed.

Objective To evaluate the effects of the cysteinyl leukotriene (CysLT) receptor antagonist montelukast on the systemic production of TGF- $\beta 1$ in patients with nasal polyposis, with or without concomitant aspirin intolerance.

Methods The sample comprised 48 individuals with diagnosis of nasal polyposis and 15 healthy controls for comparison of the baseline TGF- $\beta 1$ levels in the peripheral blood and after treatment with CysLT receptor antagonist montelukast in the nasal-polyposis group.

Results There was no difference in the change in TGF- $\beta 1$ levels after the treatment

Keywords

- rhinosinusitis

- airway

- nasal polyposis

- inflammation

- allergy with montelukast in the subgroup of patients with polyposis and asthma $(p=0.82)$ and in the subgroup with polyposis, asthma, and aspirin intolerance $(p=0.51)$.

Conclusion we found no impact of the therapy with a leukotriene receptor blocker on the production of TGF- $\beta 1$, making the antileukotriene therapy a highly questionable choice for the treatment of nasal polyposis, particularly from the standpoint of seeking to modify the remodeling process in this disease.
\end{abstract}

received

July 2, 2019

accepted

December 26, 2019

published online

April 27, 2020
DOI https://doi.org/

10.1055/s-0040-1702972. ISSN 1809-9777.

\footnotetext{
(c) 2020. Fundação Otorrinolaringologia. All rights reserved.

This is an open access article published by Thieme under the terms of the Creative Commons Attribution-NonDerivative-NonCommercial-License, permitting copying and reproduction so long as the original work is given appropriate credit. Contents may not be used for commercial purposes, or adapted, remixed, transformed or built upon. (https://creativecommons.org/ licenses/by-nc-nd/4.0/) Thieme Revinter Publicações Ltda., Rua do Matoso 170, Rio de Janeiro, RJ, CEP 20270-135, Brazil
} 


\section{Introduction}

Recent studies show that nasal polyposis (NP) is more than a chronic inflammatory disorder: it is a disease characterized by a mechanical dysfunction of the nasal mucosa, namely, a tissue laxity that leads to loss of equilibrium between hydrostatic and oncotic pressures, the mechanism responsible for limiting the formation of tissue edema. ${ }^{1-3}$

This inability to properly elevate interstitial hydrostatic pressure in the polypoid nasal mucosa is closely related to the unique makeup of its extracellular matrix, which develops as the result of an anomalous tissue remodeling process. $^{4,5}$ In this context, transforming growth factor beta 1 (TGF $\beta-1)$ plays a pivotal role in the remodeling process of abnormal tissue in cases of NP. ${ }^{6-9}$

In a previous study, ${ }^{10}$ we demonstrated that fibroblasts isolated from patients with chronic rhinosinusitis without NP exhibit increased matrix metalloproteinase 1 (MMP1) and cysteinyl leukotriene receptor 1 (CysLTR1) after stimulation with leukotriene D4 (LTD4), with an additional increase occurring in the presence of TGF- $\beta 1$. In this previous study, the CysLT receptor antagonist montelukast effectively reduced the MMP1 and CysLTR1 expression after stimulation with LTD4 or TGF- $\beta 1$.

In a recent study, we demonstrated that TGF- $\beta 1$ is reduced not only in the nasal tissue, but also in the plasma of aspirinintolerant patients, ${ }^{11}$ due to the chronic systemic inflammatory nature of this disease, which is not limited to the airways. Patients with a history of aspirin intolerance exhibit an imbalance in the production of eicosanoids characterized by an increase in proinflammatory mediators (leukotrienes) at the expense of anti-inflammatory mediators (prostaglandin E2, PGE2). ${ }^{12}$

The aspirin-intolerant subgroup of patients with NP is characterized by a more intense inflammatory process, which is reflected by higher rates of comorbidity and recurrence after treatment. Thus, it is important that the relationship between the production of leukotrienes and TGF- $\beta 1$ be assessed.

In the present study, we evaluated the effects of the CysLT receptor antagonist montelukast on the systemic production of TGF- $\beta 1$ in patients with NP, with or without concomitant aspirin intolerance.

\section{Materials and Methods}

The present study was conducted at the Department of Otolaryngology and Head and Neck Surgery of our institution between 2015 and 2017. The project was approved by the local Ethics in Research Committee under protocol number 70890617800005505. All individuals willingly agreed to take part in the study and provided written informed consent.

The sample comprised 48 individuals with a European Position (EPOS) $2012^{13}$ diagnosis of NP, and 15 healthy controls for comparison of the baseline TGF- $\beta 1$ levels in the peripheral blood.

The age of the subjects ranged from 18 to 65 years, and those who had used oral or topical corticosteroids, immu- nosuppressants, or antihistamines in the 30 days preceding the collection of peripheral blood collection and during the clinical assessment were excluded from the study.

To assess the effects of the montelukast therapy on the production of TGF- $\beta 1,20$ of the 48 patients diagnosed with NP were submitted to a treatment with montelukast for 30 days at a daily dose of $10 \mathrm{mg}$.

Of these 20 patients with NP, 9 patients with NP without asthma or aspirin intolerance, 6 also had a diagnosis of asthma, and 5 also had a diagnosis of asthma and aspirin intolerance.

The measurement of the levels of TGF- $\beta 1$ was performed in peripheral blood samples collected in 4-mL ethylenediaminetetraacetic acid (EDTA) tubes (Becton Dickinson and Company, Franklin Lakes, NJ, US) and centrifuged for 10 minutes at $1,000 \mathrm{G}$. The blood plasma was collected and stored at $-80^{\circ} \mathrm{C}$.

The plasma concentrations of TGF- $\beta 1$ were measured using TGF- $\beta 1$ MILLIPLEX MAP (EMD Millipore, St. Charles, MO, US) kits, in accordance with manufacturer instructions. Briefly, $25 \mu \mathrm{l}$ of plasma were incubated overnight with color-coded beads coated with capture antibodies for TGF- $\beta 1$ at $4^{\circ} \mathrm{C}$, with constant agitation on a plate shaker. After washing, the beads were incubated with biotinylated TGF- $\beta 1$ secondary detection antibodies for 1 hour at room temperature, followed by incubation with streptavidin-phycoerythrin for 30 minutes at room temperature, all under constant agitation on a plate shaker. Finally, the measurement was performed using a Luminex 100/200 System (Luminex Corporation, Austin, TX, US). According to the standard curves, the concentration of the respective cytokines was calculated and expressed in $\mathrm{pg} / \mathrm{ml} .^{14}$

\section{Statistical Analysis}

The statistical analyses were performed using the Statistical Package for the Social Sciences (SPSS, IBM Corp., Armonk, NY, US) software, version 22, and GraphPad Prism (GraphPad Software Inc., San Diego, CA, US) software, version 7. The nonparametric Wilcoxon test was used to assess the differences within the groups before and after the montelukast treatment. The Mann-Whitney U test was used to assess the differences in the baseline level of TGF- $\beta 1$ between two independent samples (individuals with and without NP). In all cases, values of $p<0.05$ were deemed statistically significant.

\section{Results}

There were no gender differences in the levels of TGF- $\beta 1$ in either group. The mean age was significantly higher in the NP group $(p<0.05)$

\section{Baseline TGF- $\beta 1$ Levels}

The comparison of the plasma levels of TGF- $\beta 1$ between the control and NP groups revealed no significant difference. However, there was a trend toward lower levels of TGF- $\beta 1$ in the NP group ( $p=0.09$, - Figure 1, - Table $\mathbf{1})$.

When the NP group was further subdivided into patients with NP (NP alone and NP + asthma without aspirin intolerance) and NP + aspirin intolerance, there was no statistically 


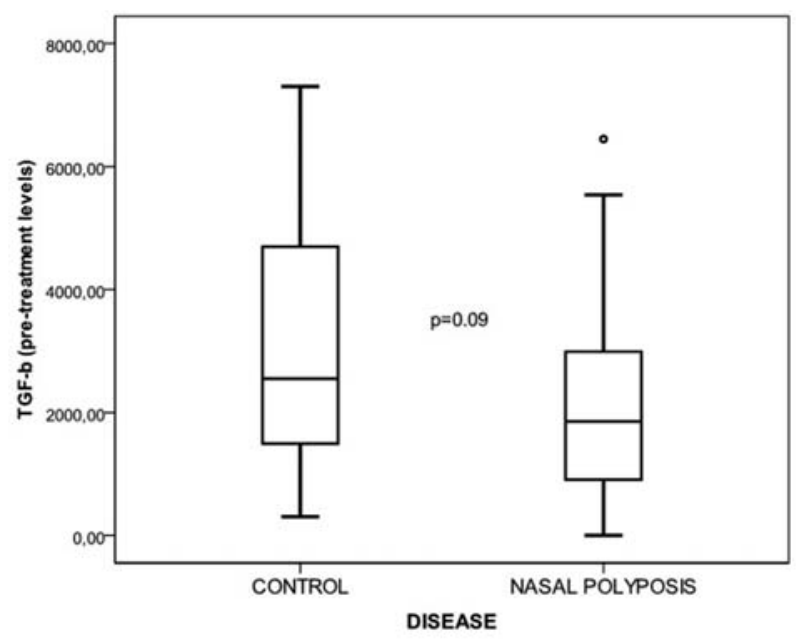

Fig. 1 Trend toward lower baseline levels of transforming growth factor beta 1 (TGF- $\beta 1$ ) in the nasal polyposis group compared to the control group.

significant difference in the baseline levels of TGF- $\beta 1$ among these subgroups.

\section{Effect of the Leukotriene Receptor Blocker Montelukast on the production of TGF- $\beta 1$}

There was no statistically significant difference in the plasma levels of TGF- $\beta 1$ in the patients with NP who underwent the montelukast $(p=0.9)$ treatment. There was also no difference in the change in TGF- $\beta 1$ levels after the treatment with montelukast in the subgroup of patients with NP and asthma $(p=0.82)$ and in the subgroup with NP, asthma, and aspirin intolerance $(p=0.51)$, - Figure 2, - Table 1.

\section{Discussion}

It is believed that NP is triggered by a chronic inflammatory process that leads to a mechanical dysfunction of the nasal mucosa in predisposed patients. ${ }^{1}$ This mechanical dysfunction is associated with a unique remodeling process, in which TGF- $\beta 1$ plays a pivotal role. ${ }^{6}$

Many studies ${ }^{7-9}$ suggest that TGF- $\beta 1$ is decreased in the polypoid nasal tissue, and systemic (plasma) levels of this cytokine have also been shown to be decreased in patients with aspirin intolerance. ${ }^{11}$

A research ${ }^{12}$ has also shown that patients with aspirin intolerance have abnormal eicosanoid production, with

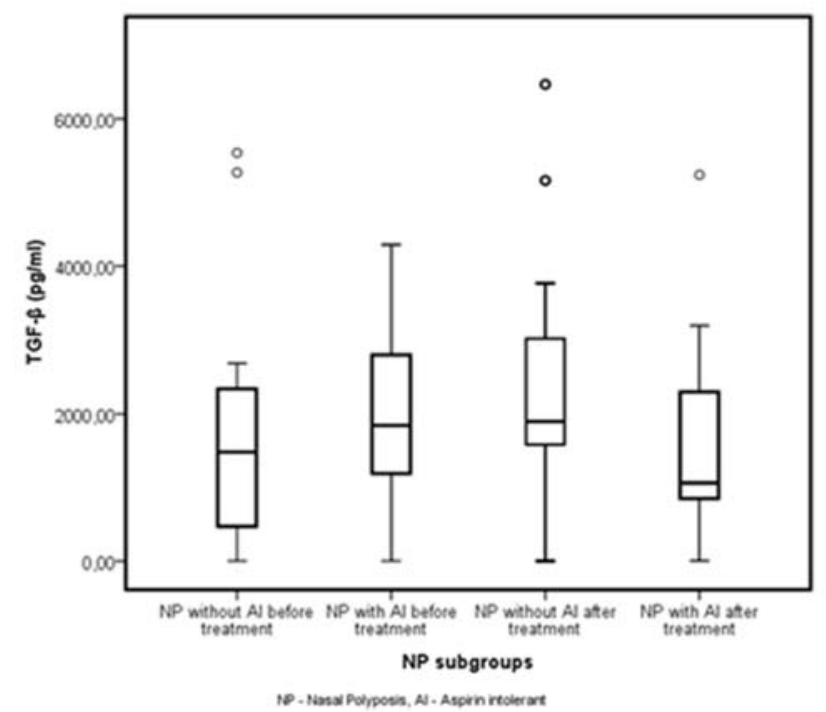

Fig. 2 Comparison of transforming growth factor beta 1 (TGF- $\beta 1$ ) levels before and after the montelukast treatment between different nasal polyposis subgroups, showing no statistical significance.

increased synthesis of leukotrienes. In NP, leukotriene receptors are overexpressed in the polyp tissue. ${ }^{15}$

In cases of chronic rhinosinusitis, LTD4 and TGF $\beta-1$ induce the expression of metalloproteinase through CysLTR $1,{ }^{10}$ and an increased expression of metalloproteinases is found in the nasal polyp tissue, such as MMP7 and MMP9. ${ }^{6}$ The close correlation between TGF- $\beta 1$ and the production of leukotrienes in cases of NP can also be highlighted by the fact that leukotrienes are found increased in NP, especially in aspirinintolerant patients, ${ }^{12}$ who present a descreased systemic expression of TGF- $\beta 1$ levels not only in the tissue, as it is usually found in cases of NP without aspirin intolerance, ${ }^{11}$ showing that the altered production of eicosanoids in aspirin-intolerant patients provokes a systemic inflammation, unlike the local inflammation found in NP. On the other hand, TGF- $\beta 1$, a protein that plays a pivotal role in the balance of fibrinolysis and fibrogenesis and, consequently, on the extracellular matrix production, ${ }^{10}$ is found decreased in nasal polypoid tissue. $^{9}$

Within this context, the present study sought to investigate whether there is a direct relationship between the exacerbated effects of leukotrienes ${ }^{16}$ and the decreased concentrations of TGF- $\beta 1$ found in cases of NP.

Table 1 Levels of transforming growth factor beta 1 (TGF- $\beta 1 ; \mathrm{pg} / \mathrm{ml}$ )

\begin{tabular}{|l|l|l|l|l|}
\hline & Minimum & Maximum & Mean & Standard deviation \\
\hline Control (baseline, healthy nasal mucosa) & 304 & 7,299 & 3,150 & 2,045 \\
\hline Nasal polyposis without aspirin intolerance (before the treatment) & 2.04 & 5,539 & 1,905 & 1,922 \\
\hline Nasal polyposis with aspirin intolerance (before the treatment) & 2.04 & 4,289 & 1,914 & 1,310 \\
\hline Nasal polyposis without aspirin intolerance (after the treatment) & 2.04 & 6,469 & 2,410 & 1,988 \\
\hline Nasal polyposis with aspirin intolerance (after the treatment) & 3.73 & 5,239 & 1,794 & 1,610 \\
\hline
\end{tabular}


In a previous study, ${ }^{10}$ we demonstrated that the association of TGF- $\beta 1$ with LTD4 in the nasal polyp tissue stimulates the production of MM1 via the leukotriene receptor.

In the present study, although we found no significant difference, there was a trend toward lower baseline levels of TGF- $\beta 1$ in the NP group compared with the healthy controls, which is consistent with the findings reported in the literature. $^{11}$

It is noteworthy that, although aspirin intolerance is characterized by its systemic nature, ${ }^{11}$ the effects of the inflammatory process in cases of NP are often exclusively localized, with no detection in the plasma mediators. Further studies are warranted, with a particular focus on measuring tissue levels of TGF- $\beta 1$, to elucidate the actual role of leukotriene receptor blockers in modifying the nasal mucosa remodeling process. Studies designed to assess quality of life and nasal symptoms after the administration of these drugs would be particularly important to demonstrate the true dimension of their potential for clinical use.

\section{Conclusion}

We found no impact of the therapy with a leukotriene receptor blocker on the production of TGF- $\beta 1$, making antileukotriene therapy a highly questionable choice for the treatment of NP, particularly from the standpoint of seeking to modify the remodeling process in this disease.

\section{Conflict of Interests}

The authors have no conflict of interests to declare.

\section{References}

1 Pezato R, Voegels RL, Pinto Bezerra TF, Perez-Novo C, Stamm AC, Gregorio LC. Mechanical disfunction in the mucosal oedema formation of patients with nasal polyps. Rhinology 2014;52 (02):162-166

2 Pezato R, Voegels RL, Stamm AC, Gregório LC. Why we should avoid using inferior turbinate tissue as control to Nasal Polyposis studies. Acta Otolaryngol 2016;136(09):973-975

3 Pezato R, Voegels RL. Why do we not find polyps in the lungs? Bronchial mucosa as a model in the treatment of polyposis. Med Hypotheses 2012;78(04):468-470
4 Gregório L, Pezato R, Felici RS, Kosugi EM. Fibrotic Tissue and Middle Turbinate Exhibit Similar Mechanical Properties. Is Fibrosis a Solution in Nasal Polyposis? Int Arch Otorhinolaryngol 2017; 21(02):122-125

5 Pezato R, Voegels RL, Pignatari S, et al. Nasal Polyposis: More than a Chronic Inflammatory Disorder-A Disease of Mechanical Dysfunction-The São Paulo Position. Int Arch Otorhinolaryngol 2019; 23(02):241-249

6 Pezato R, Balsalobre L, Lima M, et al. Convergence of two major pathophysiologic mechanisms in nasal polyposis: immune response to Staphylococcus aureus and airway remodeling. J Otolaryngol Head Neck Surg 2013;42(01):27

7 Figueiredo CR, Santos RP, Silva ID, Weckx LL. Microarray cDNA to identify inflammatory genes in nasal polyposis. Am J Rhinol 2007; 21(02):231-235

8 Watelet JB, Bachert C, Claeys C, Van Cauwenberge P. Matrix metalloproteinases MMP-7, MMP-9 and their tissue inhibitor TIMP-1: expression in chronic sinusitis vs nasal polyposis. Allergy 2004;59(01):54-60

9 Balsalobre L, Pezato R, Perez-Novo C, et al. Epithelium and stroma from nasal polyp mucosa exhibits inverse expression of TGF- $\beta 1$ as compared with healthy nasal mucosa. J Otolaryngol Head Neck Surg 2013;42(01):29

10 Pezato P, Claeys C, Holtappels G, Bachert C, Pérez-Novo CA. LTD4 and TGF- $\beta 1$ induce the expression of metalloproteinase- 1 in chronic rhinosinusitis via a cysteinyl leukotriene receptor 1-related mechanism. Sinusitis 2016;1(01):65-75

11 Pezato R, Świerczyńska-Krępa M, Niżankowska-Mogilnicka E, et al. Systemic expression of inflammatory mediators in patients with chronic rhinosinusitis and nasal polyps with and without Aspirin Exacerbated Respiratory Disease. Cytokine 2016;77:157-167

12 Pezato R, Świerczyńska-Krępa M, Niżankowska-Mogilnicka E, Derycke L, Bachert C, Pérez-Novo CA. Role of imbalance of eicosanoid pathways and staphylococcal superantigens in chronic rhinosinusitis. Allergy 2012;67(11):1347-1356

13 Fokkens WJ, Lund VJ, Mullol J, et al. European Position Paper on Rhinosinusitis and Nasal Polyps 2012. Rhinol. Suppl. 3 p preceding table of contents, 1-298 (2012

14 Shevchenko I, Karakhanova S, Soltek S, et al. Low-dose gemcitabine depletes regulatory $\mathrm{T}$ cells and improves survival in the orthotopic Panc02 model of pancreatic cancer. Int J Cancer 2013; 133(01):98-107

15 Pérez-Novo CA, Claeys C, Van Cauwenberge P, Bachert C. Expression of eicosanoid receptors subtypes and eosinophilic inflammation: implication on chronic rhinosinusitis. Respir Res 2006;7:75

16 Pérez-Novo CA, Watelet JB, Claeys C, Van Cauwenberge P, Bachert C. Prostaglandin, leukotriene, and lipoxin balance in chronic rhinosinusitis with and without nasal polyposis. J Allergy Clin Immunol 2005;115(06):1189-1196 